\title{
Successful experience of using adaptive support ventilation (ASV) in the patient with suspected COVID pneumonia
}

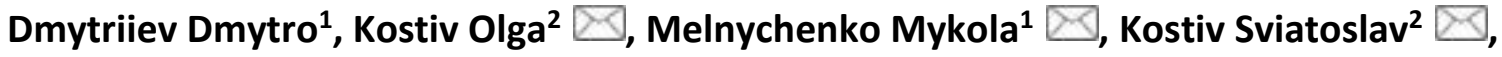 \\ Dmytriiev Kostiantyn ${ }^{1}$
}

Author affiliations:

1. Vinnitsa National Medical University n.a. M.I Pirogov, Pyrohova St, 56, Vinnytsia, Vinnytsia Oblast, Ukraine, 21018

2. Ternopil National Medical University n.a. I. Gorbachevsky, Voli Square, 1, Ternopil, Ternopil Oblast, Ukraine, 46002

Correspondence: Dmytriiev Dmytro; E-mail: dmytrodmytriiev@gmail.com; Phone: +380674309449

\begin{abstract}
An interesting clinical case of suspected COVID-19 pneumonia in a patient with diabetes mellitus is considered in the article. This case deservest attention of anesthesiologists, especially today, during the COVID-19 epidemic. An important role in timely diagnosis belongs to the CT scan, as the X-ray does not always diagnose viral pneumonia. In our case, we adhered to the principles of restrictive infusion therapy, early intubation, protective ventilation and early weaning of the patient from the respirator. The article describes the successful experience of using the ASV intelligent ventilation mode - from intubation to extubation. We recommend you to use ASV in patients with suspected COVID-19 pneumonia and L-type to achieve protective ventilation, rapid weaning, and low risk of complications.
\end{abstract}

Key words: COVID-19, ARDS, CT scan, early intubation, ASV, protective ventilation, early weaning

Citation: Dmytriev D, Kostiv O, Melnychenko MV, Kostiv S, Dmytriiev K. Successful experience of using adaptive support ventilation (ASV) in the patient with suspected COVID pneumonia. Anaesth. Pain intensive care 2021;25(1):111-117; DOI 10.35975/apic.v25i1.1212

Received: 5 April 2020, Reviewed: 14 June 2020, Accepted: 12 January 2021

\section{Introduction}

According to the World Health Organization (WHO), new forms of viral diseases continue to emerge and are a challenge for the Health Care system. Over the past twenty years, several viral epidemics have been recorded, such as Severe Acute Respiratory Syndrome Coronavirus (SARS-CoV) in 2002-2003, H1N1 influenza virus in 2009, and Middle East Respiratory Syndrome Coronavirus (MERS-CoV) in 2012. Today, the Novel Severe Acute Respiratory Syndrome Coronavirus 2 (SARSCoV-2) is the cause of the 2019 Pandemic Coronavirus Disease (COVID-19), which affects thousands of people worldwide. Manifestations of respiratory syndrome with 2019-nCoV virus infection can range from complete absence of symptoms to severe pneumonia with respiratory failure, which can lead to death. Studies have shown that people with underlying comorbidities like diabetes are more prone to experience adverse outcomes of COVID-19. ${ }^{1,2}$

The most common and severe complication in patients with COVID-19 is acute hypoxic respiratory failure or acute respiratory distress syndrome (ARDS) requiring oxygen and ventilation therapy. ${ }^{3}$ The Berlin definition of the 2012 announcement defines the severity of ARDS in the oxygenation index. ${ }^{4}$ Critically ill patients need intubation and mechanical ventilation., ${ }^{3,5}$

In the literature there have been descriptions of two different phenotypes of the virus presentation among hospitalized patients and particularly those requiring mechanical ventilation. The H-type is characterized by high lung elastance, high weight, 
and high recruitability. The L-type has high compliance, low V/Q ratio, and low lung recruitability. ${ }^{6}$

WHO has classified patients with diabetes mellitus (DM) to the COVID-19 risk group of the severe disease, so the occurrence of pneumonia in this group of patients during the epidemic may be considered as a potential case of COVID-19.

It is still unknown whether there is a difference in the risk of patients with type 1 and type 2 diabetes. However, age, the presence of comorbidities and features of treatment play an important role in risks assessment of infectious complications in intensive care units. $^{7}$

\section{Case report}

Patient S. aged 45 years with type II diabetes mellitus was admitted to a regional hospital March 11, 2020 with complaints of 3-day subfebrile fever, cough, shortness of breath, discomfort in the chest, runny nose, fatigue. Medical and social history was unremarkable. Chest X-rays - signs of bilateral roots infiltration. (Figure 1)

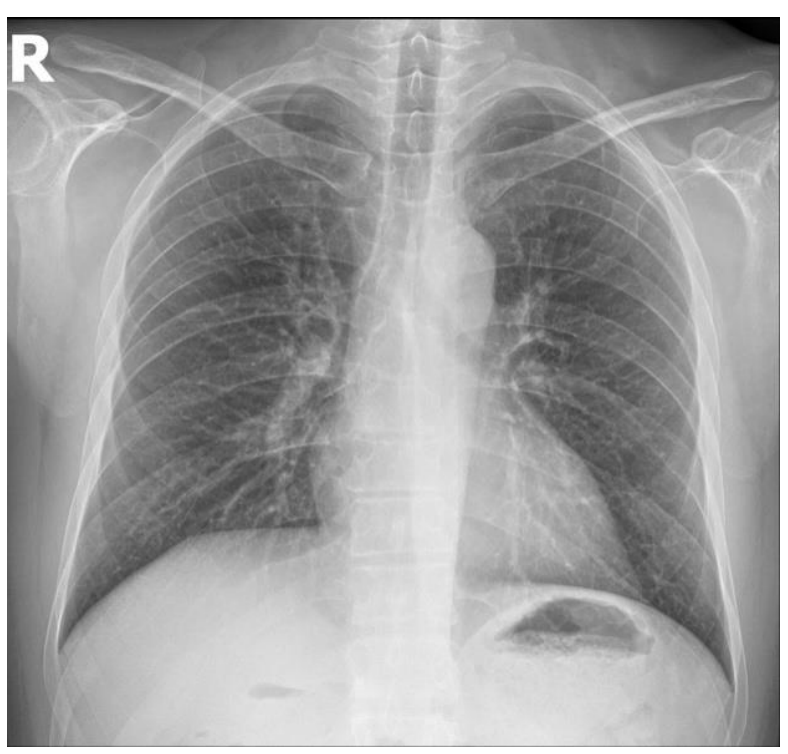

Figure 1: Chest X-rays (direct projection)

In 6 days the clinical picture worsened - the temperature rose to $38.8^{\circ} \mathrm{C}$, and shortness of breath increased.

The patient was transferred to the intensive care unit (ICU). Objectively, the skin was pale pink, RR - 28 / min, $\mathrm{SpO}_{2}$ - 93\%. Auscultatory - symmetrical weakened vesicular respiration. NIBP - 130/80
mmHg. Ps - 96/min, rhythmically, satisfactory and no other remarkable findings. APACHE II score was used for risk stratification - 10 points mean $15 \%$ estimated non-operative mortality.

Chest X-rays was re-performed - infiltration of roots increased (Figure 2). CITO TEST Influenza A + B negative. Given the pandemic of Coronavirus and clinical course, the patient was suspected of viral COVID pneumonia. Unfortunately, we had no possibility to do SARS-CoV-2 testing.

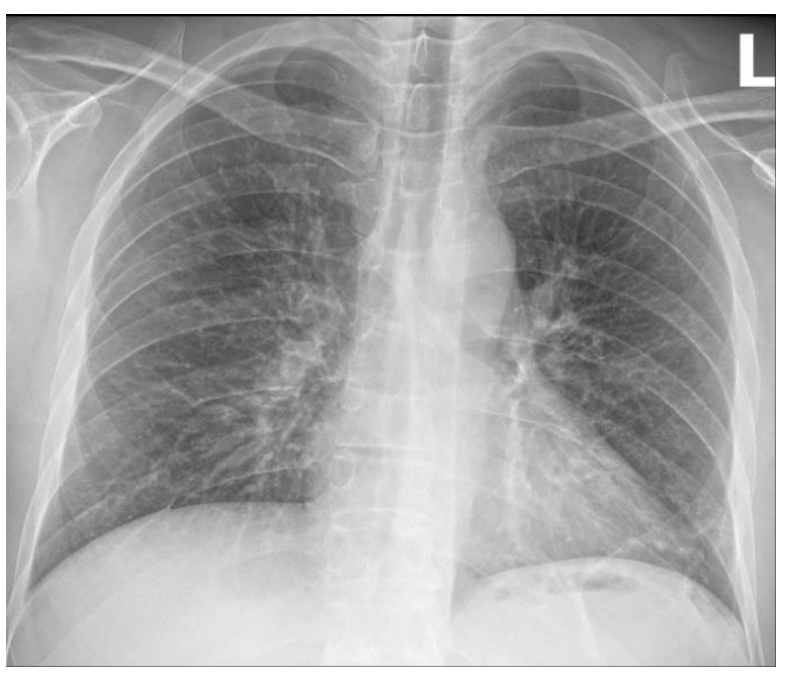

Figure 2: Chest X-rays (direct projection)

The patient was started oxygen therapy through a face mask with a flow of $71 / \mathrm{min}$. Restrictive infusion therapy $(20 \mathrm{ml} / \mathrm{kg} /$ day $)$ was started, for prevention the accession of bacterial flora ceftriaxone $1 \mathrm{~g}$ was administered twice a day. Within 2 days of treatment, the patient's condition did not improve - a lung CT scan was performed on which there were signs of viral pneumonia (Figure 3, Figure 4):

- Areas of decrease in the transparency of lung tissue by the type of frosted glass.

- Inhomogeneous areas of parenchyma consolidation.

- nodular focal shadows.

These CT findings are typical in individuals with COVID- $19,{ }^{8}$ so our suspicions were confirmed. After the examination, a correction of treatment was carried out - oseltamivir was prescribed - 75mg twice a day, azithromycin $500 \mathrm{mg}$ once a day, amikacin $500 \mathrm{mg}$ - once a day, according to the microbiological passport of the department. ${ }^{9}$ 


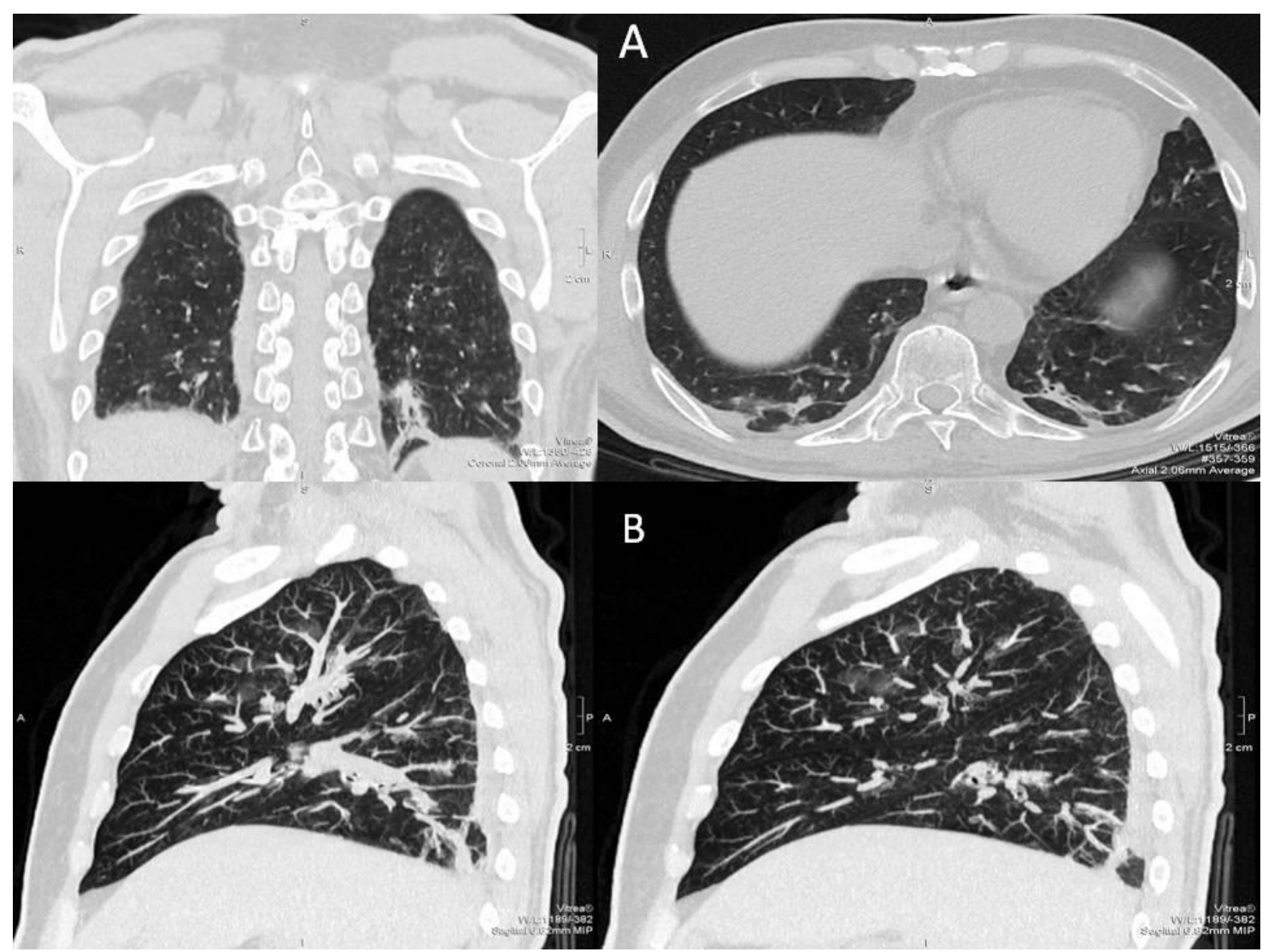

Figure 3: CT scan of the lungs (A. Direct projection and cross-section projection; B. Lateral projection)

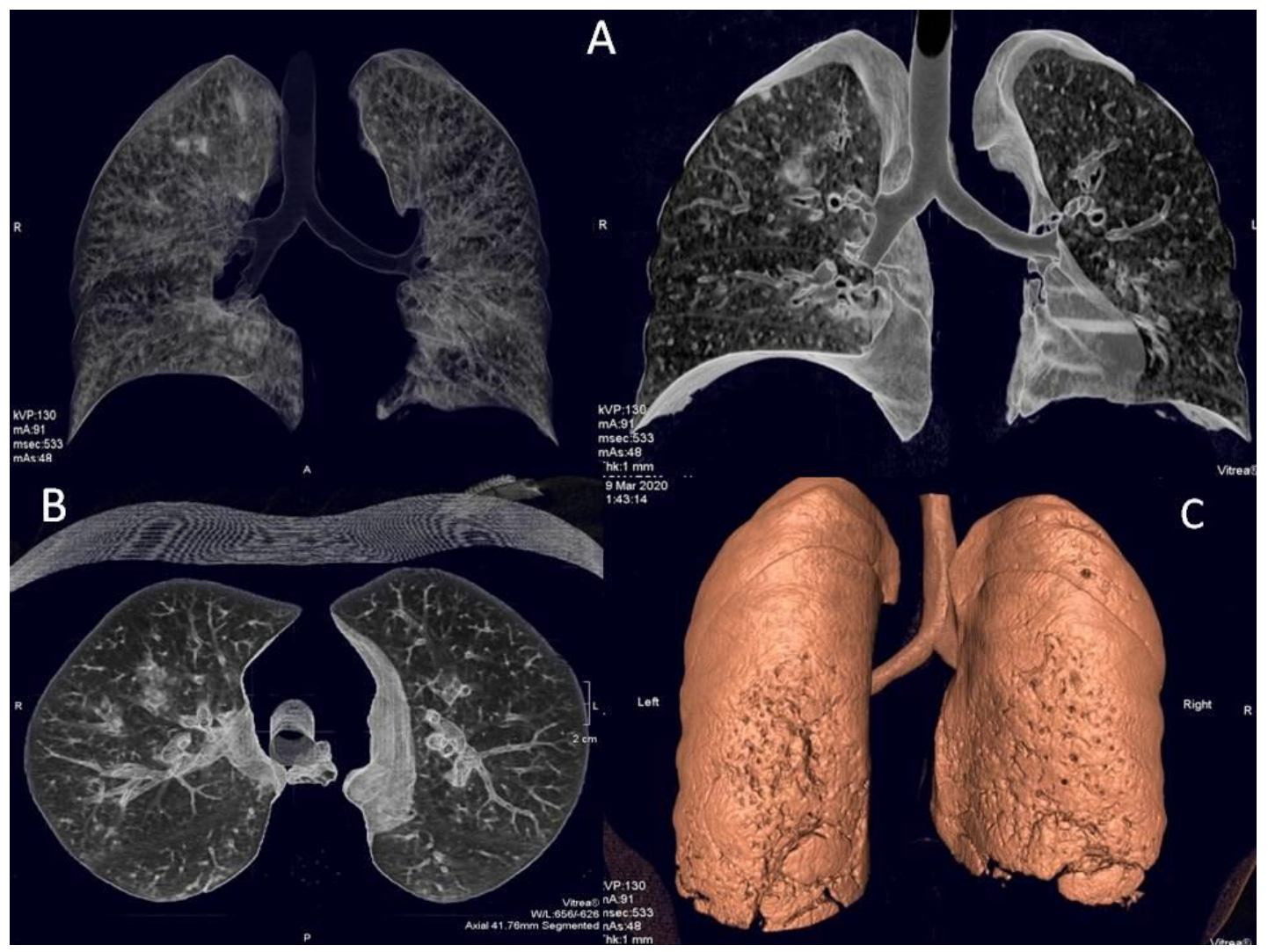

Figure 4: CT scan with 3D lung reconstruction (A. in direct projection; B. Cross-section, C. 3D reconstruction) 
Table 1: Gas exchange parameters and ventilator settings

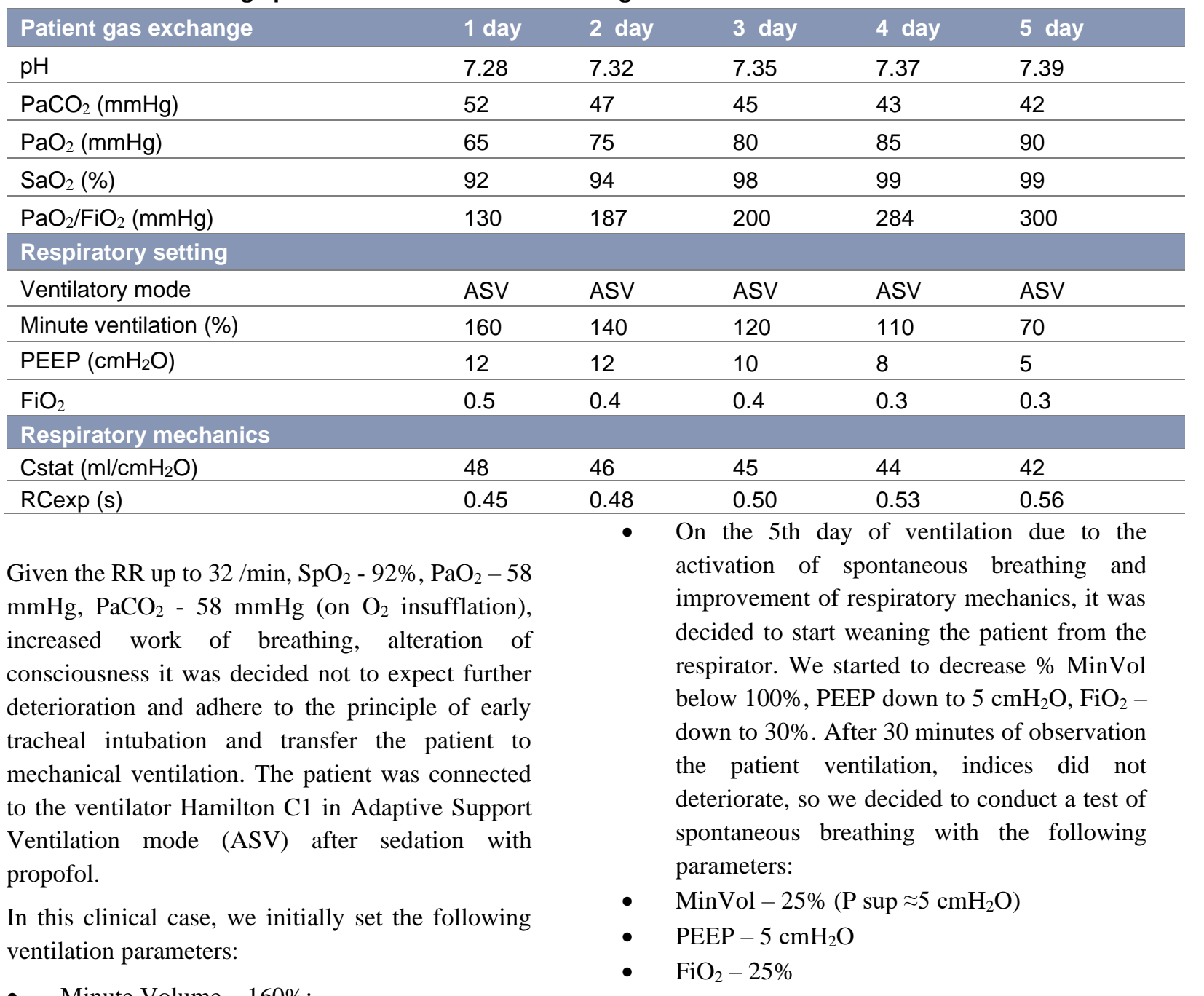

- $\quad$ Minute Volume - 160\%;

- $\mathrm{PEEP}-12 \mathrm{cmH}_{2} \mathrm{O}$

- $\mathrm{FiO}_{2}-50 \%$

The ventilator successfully adapted to the patient's spontaneous breathing attempts in ASV mode. From the next day, the clinical and laboratory picture began to improve. Gradually we decreased the degree of respiratory support. Indicators of gas exchange and setting of ventilation parameters on Hamilton C1 - Table 1.

During the entire ASV ventilation period, the mean values were protective according to the ARDSnet protocol:

- Tidal volume - $6.5 \mathrm{ml} / \mathrm{kg}$ IBW (4 - $8 \mathrm{ml} / \mathrm{kg}$ IBW according to the ARDSnet protocol);

- $\quad$ Plateau pressure (Pplat) - $23 \mathrm{cmH}_{2} \mathrm{O}$ (Pplatu < $30 \mathrm{cmH}_{2} \mathrm{O}$ according to the ARDSnet protocol);

- Driving pressure - $9 \mathrm{cmH}_{2} \mathrm{O}\left(<15 \mathrm{cmH}_{2} \mathrm{O}\right.$ according to the ARDSnet protocol).

After that, the patient was attentively observed for 40 minutes - the ventilation status did not deteriorate, so it was decided to extubate the patient. Further treatment was performed according to the appointment sheet and on the 10th day of treatment the patient was transferred to a somatic hospital.

\section{Discussion}

In this clinical case, a patient with diabetes has contracted viral pneumonia. Given the COVID-19 epidemic and the fact that patients with diabetes are at risk group, CITO TEST Influenza A + B negative we followed increased safety precautions. Viral pneumonia has a wide range of clinical course - from asymptomatic carrier to severe disease, even death. ${ }^{10-12}$ A common and noticeable complication of COVID-19 pneumonia is acute hypoxemic respiratory failure requiring oxygen and ventilation therapy.

This case is evidence that if there is no clear sign of viral pneumonia on the radiograph, the diagnosis can 
be quickly and unequivocally confirmed on the CT scan. More and more patients are undergoing CT scans when there is a clinical suspicion of pneumonia with normal or questionable radiological findings. ${ }^{13-19}$ In a study of 87 patients with febrile fever and neutropenia, it was noted that CT had a pulmonary lesion that was not observed on the radiograph in $50 \%$ of patients. ${ }^{20}$ To date, the only way to confirm the COVID-19 phenotypes is through high-resolution computed tomography. ${ }^{21}$

The diagnosis of ARDS was made according to the following Berlin definition criteria: (1) presence of acute hypoxemic respiratory failure, (2) worsening respiratory symptoms; (3) bilateral opacities on chest x-ray or CT not fully explained by effusions, lobar or lung collapse, or nodules; and (4) cardiac failure not the primary cause of acute respiratory failure.

There are two phenotypes with COVID-19 ARDS. These phenotypes, known as "L-type" and "Htype", report what appear to be two distinct presentations with drastically different management. ${ }^{6}$ We presented a case of a patient with suspected COVID-19 who approaching to L-type due to his lung compliance and CT-scan.

Conservative infusion therapy tactics should be followed in patients with ARDS. ${ }^{22}$ The use of corticosteroids should be avoided because studies have shown that influenza virus patients have increased mortality and increased hospital-acquired infections. ${ }^{23}$ - 25 However, a recent study suggests that early administration of dexamethasone may reduce the overall mortality and duration of mechanical ventilation in patients with ARDS. ${ }^{26}$

Initially, the treatment for severe respiratory failure included early intubation and invasive ventilation, as this was deemed preferable to be more effective than Non-Invasive Ventilation (NIV). ${ }^{27}$ Both NIV and HFNO are classed as an aerosol generating procedure and increase the risk of viral transmission. We had no possibility to treat patients within a negative pressure environment.

So in our case, ARDS was timely diagnosed and early intubation performed with ventilation without expecting a significant deterioration of the patient's condition. One study found that among patients with ARDS who needed intubation, survival was better in the group of patients who had an early intubation. ${ }^{28}$

Mechanical ventilation sometimes is necessary for maintaining respiration in patients with ARDS, but if it isn't protective, it may cause lung injury ventilator-associated lung injury. ${ }^{29}$

Guides on protective ventilation of the lungs at ARDS emphasize: 1) Tidal volume - $4-8 \mathrm{ml} / \mathrm{kg}$ IBW; 2) $\mathrm{RR} \leqslant 35 / \mathrm{min}$; (3) $\mathrm{P}$ plateau $\leqslant 30 \mathrm{cmH}_{2} \mathrm{O}$; 4) $\mathrm{PEEP} \geq 5 \mathrm{cmH}_{2} \mathrm{O} .{ }^{30-33}$ The adequate tidal volume of each patient should be adjusted according to the plateau pressure, PEEP, thoracoabdominal compliance and respiratory effort. $^{34}$ Driving pressure ( $\mathrm{P}$ plateau - PEEP) below $12-15 \mathrm{~cm} \mathrm{H}_{2} \mathrm{O}$ is recommended, adjusting tidal volume and PEEP in patients who do not breathe on their own. ${ }^{35}$

In our case, we decided to use ASV ventilation mode, because in this mode the machine automatically analyzes the state of pulmonary mechanics and the main parameters of external ventilation. Based on these data, it provides support for a given respiratory minute volume - with the safest ventilation parameters. ${ }^{36,37}$ In addition in ASV mode it doesn't matter which phenotype is presented in patient with COVID-19- in both cases the optimal ventilation parameters will be selected according to individual pulmonary compliance and resistance.

Weaning is important in the care of patients on mechanical ventilation. ${ }^{38}$ The ASV - closed-loop ventilation mode, which can ventilate in pressurecontrolled ventilation and pressure-support ventilation modes, can be used for weaning in acute and chronic respiratory failure. ${ }^{39}$ Weaning in ASV mode shows good results. ${ }^{40}$ The shortened ASV weaning time in our study may be due to the automation of safe ventilation, the reduction of manipulation, and the time spent on parameters regulation. ${ }^{41}$

\section{Conclusions}

COVID-19 pneumonia today is a new challenge for humanity. Patients with diabetes are at increased risk. Successful treatment depends on timely diagnosis. A special place is given to CT when the conclusion of a radiograph is ambiguous. Conservative infusion therapy should be followed when treating such patients. Patients with ARDS who require mechanical ventilation should be followed by the principles of protective ventilation.In our case, we applied the ASV mode for the entire ventilation time - from intubation to extubation. It was also noted that the use of protocol algorithms for weaning from ventilation can reduce its duration compared to weaning based on the experience of a physician. 
Our clinical case confirms that ASV is the mode of choice in patients with suspected COVID-19 pneumonia and L-type because it provides protective ventilation, rapid weaning, and low risk of complications.

\section{Conflict of interest}

None declared by the authors

\section{Authors' contribution}

DD: Concept, conduct of the study, manuscript editing

KO, MM: Conduct of the study, manuscript editing

KS, DK: Manuscript editing

\section{References}

1. Wang D, Hu B, Hu C, et al. Clinical characteristics of 138 hospitalized patients with 2019 novel coronavirus-infected pneumonia in Wuhan, China. JAMA 2020. DOI:10.1001/jama.2020.1585

2. Guan WJ, Liang WH, Zhao Y, et al. Comorbidity and its impact on 1590 patients with Covid-19 in China: a nationwide analysis. Eur Respir J 2020. DOI: 10.1183/13993003.00547-2020

3. Yang, $X, Y u, Y, X u$, J, Shu, H, Xia, J, Liu, H, et al. Clinical course and outcomes of critically ill patients with SARS-CoV-2 pneumonia in Wuhan, China: A single-centered, retrospective, observational study Lancet Respir Med 2020 [Epub ahead of print]. DOI: 10.1016/S2213-2600(20)30079-5

4. Definition Task Force ARDS. Acute respiratory distress syndrome: the Berlin definition. JAMA. 2012;307:2526-33. DOI: 10.1001/jama.2012.5669

5. Wang, D, Hu, B, Hu, C, Zhu, F, Liu, X, Zhang, J, et al. Clinical characteristics of 138 hospitalized patients with 2019 novel coronavirus-infected pneumonia in Wuhan, China JAMA 2020 [Epub ahead of print]. DOI:10.1001/jama.2020.15857.

6. Gattinoni DC, Caironi P, Busana M, et al. COVID-19 pneumonia: different respiratory treatment for different phenotypes?. J Intens Care Med. 2020. DOI: 10.1007/s00134-020-06033-2

7. Wang D, Hu B, Hu C, et al. Clinical characteristics of 138 hospitalized patients with 2019 novel coronavirus-infected pneumonia in Wuhan, China. JAMA 2020. DOI:10.1001/jama.2020.1585

8. Guan WJ, Liang WH, Zhao Y, et al. Comorbidity and its impact on 1590 patients with Covid-19 in China: a nationwide analysis. Eur Respir J 2020. DOI: 10.1183/13993003.00547-2020

9. Yang, $X, Y u, Y, X u, J$, Shu, H, Xia, J, Liu, H, et al. Clinical course and outcomes of critically ill patients with SARS-CoV-2 pneumonia in Wuhan, China: A single-centered, retrospective, observational study Lancet Respir Med 2020 [Epub ahead of print]. DOI: 10.1016/S2213-2600(20)30079-5
10. Definition Task Force ARDS. Acute respiratory distress syndrome: the Berlin definition. JAMA. 2012;307:2526-33. DOI: 10.1001/jama.2012.5669

11. Wang, D, Hu, B, Hu, C, Zhu, F, Liu, X, Zhang, J, et al. Clinical characteristics of 138 hospitalized patients with 2019 novel coronavirus-infected pneumonia in Wuhan, China JAMA 2020 [Epub ahead of print]. DOI:10.1001/jama.2020.15857.

12. Gattinoni DC, Caironi P, Busana M, et al. COVID-19 pneumonia: different respiratory treatment for different phenotypes?. J Intens Care Med. 2020. DOI: 10.1007/s00134-020-06033-2

13. Nazarchuk OA, Dmytriiev DV, Dmytriev KD, Nazarchuk HH, Zaletskiy BV. Characteristics of infectious complications in critically ill patients. Wiad Lek. 2018;71(9):1784-1792. PMID: 30737942.

14. COVID-19: statement from the British Society of Thoracic Imaging (BSTI) 6 March 2020. https://www.bsti.org.uk/tandards-clinicalguidelines/clinical-guidelines/covid-19-bstistatement-nd-guidance/

15. Nahaichuk VI, Nazarchuk OA, Osadchuk NI, Dmytriiev DV, Nazarchuk HH. The analytical prognosis of the susceptibility to aminoglycosides and doxycycline inacinetobacter baumanniiisoolated from burns of intensive care unit patients. Wiad Lek. 2018;71(3 pt 2):705-709. PMID: 29783252.

16. Guan, WJ, Ni, ZY, Hu, Y, Liang, WH, Ou, CQ, He, JX, et al. Clinical characteristics of coronavirus disease 2019 in China N Engl J Med 2020[Epub ahead of print]. DOI: 10.1056/NEJMoa2002032

17. Huang, C, Wang, Y, Li, X, Ren, L, Zhao, J, Hu, Y et al. Clinical features of patients infected with 2019 novel coronavirus in Wuhan, China Lancet 2020; 395:497-506 DOI:https://doi.org/10.1016/S0140-6736(20)30183-5

18. Chen, N, Zhou, M, Dong, X, Qu, J, Gong, F, Han, Y, et al. Epidemiological and clinical characteristics of 99 cases of 2019 novel coronavirus pneumonia in Wuhan, China: A descriptive study Lancet 2020; 395:507-13 DOl:https://doi.org/10.1016/S0140-6736(20)30211-7

19. Kotloff RM, Ahya VN, Crawford SW. Pulmonary complications of solid organ and hematopoietic stem cell transplantation. Am J Respir Crit Care Med. 2004 Jul 1;170(1):22-48. DOI: $10.1164 / \mathrm{rccm} .200309-$ 1322SO. Epub 2004 Apr 7. PMID: 15070821.

20. Demirkazik FB, Akin A, Uzun O, Akpinar MG, Ariyürek MO. CT findings in immunocompromised patients with pulmonary infections. Diagn Interv Radiol. 2008 Jun;14(2):75-82. PMID: 18553280.

21. Aquino SL, Dunagan DP, Chiles C, Haponik EF. Herpes simplex virus 1 pneumonia: patterns on CT scans and conventional chest radiographs. J Comput Assist Tomogr. 1998 Sep-Oct;22(5):795-800. DOI: 10.1097/00004728-199809000-00024. PMID: 9754119.

22. Gulati M, Kaur R, Jha V, Venkataramu NK, Gupta D, Suri S. High-resolution CT in renal transplant patients with suspected pulmonary infections. Acta Radiol. 2000 May;41(3):237-41. DOI: 10.1080/028418500127345415. PMID: 10866078. 
23. Franquet T. Imaging of pneumonia: trends and algorithms. Eur Respir J. 2001 Jul;18(1):196-208. DOI: $10.1183 / 09031936.01 .00213501$. PMID: 11510793.

24. Franquet Franquet $T$, Müller NL, Giménez $A$, Martínez S, Madrid M, Domingo P. Infectious pulmonary nodules in immunocompromised patients: usefulness of computed tomography in predicting their etiology. J Comput Assist Tomogr. 2003 JulAug;27(4):461-8. DOI: 10.1097/00004728200307000-00001. PMID: 12886125.

25. Logan PM, Primack SL, Staples C, Miller RR, Müller $\mathrm{NL}$. Acute lung disease in the immunocompromised host. Diagnostic accuracy of the chest radiograph. Chest. 1995 Nov;108(5):1283-7. DOI: 10.1378/chest.108.5.1283. PMID: 7587430.

26. Heussel CP, Kauczor HU, Heussel G, Fischer B, Mildenberger $P$, Thelen $M$. Early detection of pneumonia in febrile neutropenic patients: use of thinsection CT. AJR Am J Roentgenol. 1997 Nov;169(5):1347-53. 10.2214/ajr.169.5.9353456. PMID: 9353456.

27. Mclnnes, L. \& Healy, J. UMAP: Uniform Manifold Approximation and Projection for Dimension Reduction. (2018) https://arxiv.org/abs/1802.03426

28. Rhodes, A, Evans, LE, Alhazzani, W, Levy, MM, Antonelli, M, Ferrer, $R$ et al. Surviving sepsis campaign: International Guidelines for Management of Sepsis and Septic Shock: 2016. Intensive Care Med 2017; 43:304-77 Epub 2017 Jan 18. PMID: 28101605. DOI: $10.1007 / \mathrm{s} 00134-017-4683-6$.

29. Martin-Loeches, I, Lisboa, T, Rhodes, A, Moreno, RP, Silva, E, Sprung, C, et al. ESICM H1N1 Registry Contributors ESICM H1N1 Registry Contributors, Use of early corticosteroid therapy on ICU admission in patients affected by severe pandemic ( $\mathrm{H} 1 \mathrm{~N} 1) \mathrm{V}$ influenza A infection. Intensive Care Med 2011; 37:272-83 DOI: 10.1007/s00134-0102078-z.

30. Rodrigo, C, Leonardi-Bee, J, Nguyen-Van-Tam, J, Lim, WS . Corticosteroids as adjunctive therapy in the treatment of influenza. Cochrane Database Syst Rev 2016; 3:CD010406. 10.1002/14651858.CD010406.pub3

31. Lansbury LE, Rodrigo C, Leonardi-Bee J, NguyenVan-Tam J, Shen Lim W. Corticosteroids as Adjunctive Therapy in the Treatment of Influenza: An Updated Cochrane Systematic Review and Metaanalysis. Crit Care Med. 2020 Feb;48(2):e98-e106. DOI: $\quad 10.1097 / C C M .0000000000004093$. PMID: 31939808.

32. Villar, J, Ferrando, C, Martínez, D, Ambrós, A, Muñoz, T, Soler, JA, et al. Dexamethasone treatment for the acute respiratory distress syndrome: A multicentre, randomised controlled trial. Lancet Respir Med 2020; 8:267-76. DOI: 10.1016/S22132600(19)30417-5

33. World Health Organization . 2020. Clinical management of severe acute respiratory infection (SARI) when COVID-19 disease is suspected.

34. Kangelaris KN, Ware LB, Wang CY, et al. Timing of Intubation and Clinical Outcomes in Adults With Acute Respiratory Distress Syndrome. Crit Care Med.
2016;

DOI:10.1097/CCM.0000000000001359

35. Parker JC, Hernandez LA, Peevy KJ. Mechanisms of ventilator-induced lung injury. Crit Care Med. 1993 Jan;21(1):131-43. DOI: 10.1097/00003246199301000-00024. PMID: 8420720.

36. Petrucci $\mathrm{N}$, De Feo C. Lung protective ventilation strategy for the acute respiratory distress syndrome. Cochrane Database Syst Rev. 2013 Feb 28;2013(2):CD003844. DOI: 10.1002/14651858.CD003844.pub4. PMID: 23450544; PMCID: PMC6517299.

37. Brower RG, Matthay MA, Morris A, Schoenfeld D, Thompson BT, Wheeler A. Ventilation with lower tidal volumes as compared with traditional tidal volumes for acute lung injury and the acute respiratory distress syndrome. N Engl J Med. 2000 May 4;342(18):13018. DOI: 10.1056/NEJM200005043421801. PMID: 10793162.

38. The Acute Respiratory Distress Syndrome Network. Ventilation with lower tidal volumes as compared with traditional tidal volumes for acute lung injury and the acute respiratory distress syndrome. $\mathrm{N}$ Engl $\mathrm{J}$ Med. 2000;342:1301-8. 10.1056/NEJM200005043421801

39. Briel M, Meade M, Mercat A, Brower RG, Talmor D, Walter SD, et al. Higher vs lower positive endexpiratory pressure in patients with acute lung injury and acute respiratory distress syndrome: systematic review and meta-analysis. JAMA. 2010;303:86573. DOI:10.1001/jama.2010.218

40. Sulemanji D, Marchese A, Garbarini P, Wysocki M, Kacmarek RM. Adaptive support ventilation: an appropriate mechanical ventilation strategy for acute respiratory distress syndrome? Anesthesiology. 2009 Oct:111(4):863-70. DOI: 10.1097/ALN.0b013e3181b55f8f. PMID: 19741490.

41. Amato, MB, Meade, MO, Slutsky, AS, Brochard, L, Costa, EL, Schoenfeld, DA, et al. Driving pressure and survival in the acute respiratory distress syndrome. N Engl J Med 2015; 372:747-55 DOI: 10.1056/NEJMsa1410639. PMID: 25693014. 